\title{
Learning in therapeutic EUS
}

\author{
Marc Giovannini ${ }^{1}$ \\ ${ }^{1}$ Department of Medico-Surgical, Paoli-Calmettes Institute, Marseille, France
}

The development of linear sectorial array EUS scopes in the early 1990 brought a new approach to the diagnostic and therapeutic dimensions of EUS capabilities, opening the possibility to perform puncture over a direct ultrasonographic guidance. Therapeutic EUS (TEUS) encompasses different procedures such as EUS-guided biliary drainage, ${ }^{[1,2]}$ drainage of pancreatic fluid collections, ${ }^{[3,4]}$ pancreatic duct drainage, ${ }^{[5]}$ gallbladder drainage, ${ }^{[6]}$ EUS-guided gastroenterostomy, ${ }^{[7,8]}$ EUS-guided pancreatic tumor ablation. ${ }^{[9]}$

As percutaneous transhepatic biliary drainage (PTBD) is mostly performed by well-trained interventional radiologists in most countries, it is still debatable if gastroenterologists should be allowed to perform PTBD after ERCP failed cannulation. ${ }^{[10]}$

This has implication in terms of the volume of cases and the learning curve to become skillful in TEUS. Training in interventional EUS procedures requires deep knowledge of the accessories used. For example, one needs to know the type of needle to be used and how to choose the correct guidewire. The trainee needs to learn manipulation of the guidewire and stents during the therapeutic procedures.

The basic technique of interventional EUS is quite similar to those of ERCP or PTBD procedures. Learning

\begin{tabular}{|l|l|}
\hline \multicolumn{2}{|c|}{ Access this article online } \\
\hline Quick Response Code: & Website: \\
\hline & www.eusjournal.com \\
\cline { 2 - 2 } & DOI: \\
\hline
\end{tabular}

ERCP and TEUS in parallel is the key point. EUS biliary drainage is now the first choice after ERCP failure. However, if the first step of the procedure is purely "ultrasonic" (puncture of the dilated bile duct), the other steps are very closed to ERCP. Actually, biliary drainage using EUS- and EUS-guided puncture of the bile duct (common bile duct or left hepatic duct), and EUS-guided rendezvous techniques are available options in some references centers. We classified the different approaches such as (a) intrahepatic approach (hepaticogastrostomy, puncture for rendezvous technique, and placement of a transhepatic anterograde self-expandable metal stent and (b) extrahepatic approach (choledocoduodenostomy, puncture for rendezvous technique through main bile duct).

It is the same for pancreatic collection drainage, pancreatic duct stenting, cholecystoduodenostomy, and gastrojejunal anastomosis. However, before starting TEUS, the endosonographer should perform routinely EUS-FNA and FNB with a high success rate (around $90 \%$ ) and to be able to put a needle in a $5-\mathrm{mm}$ diameter lesion.

The first TEUS procedure to learn is the pancreatic collection drainage using cystostome and double pigtail

This is an open access journal, and articles are distributed under the terms of the Creative Commons Attribution-NonCommercial-ShareAlike 4.0 License, which allows others to remix, tweak, and build upon the work non-commercially, as long as appropriate credit is given and the new creations are licensed under the identical terms.

How to cite this article: Giovannini M. Learning in therapeutic EUS. Endosc Ultrasound 2021;10:317-8.

Address for correspondence

Dr. Marc Giovannini, Department of Medico-Surgical, Paoli-Calmettes Institute, Marseille, France.

E-mail: uemco@ipc.unicancer.fr

Received: 2021-09-28; Accepted: 2021-09-29; Published online: 2021-10-18 
stents to manipulate catheter, guidewire, and stents with EUS scope which is a little bit different than a duodenoscope. After 20-30 collections drainage, the next procedure should be the cholecystoduodenostomy, then the biliary drainage (choledocoduodenostomy and hepaticogastrostomy), then EUS-guided pancreaticogastrostomy, and the gastrojejunal anastomosis.

However, interventional EUS procedures carry additional complications such as bile leakage, stent migration, bleeding, and even perforation. ${ }^{[11,12]}$ Because of these potential risks, hands-on training of interventional EUS in real-life patients has become a huge challenge. Some centers have tried to develop phantom models for the purpose of training intervention procedures. ${ }^{[13-15]}$ The performance of interventional EUS procedures requires high skill and expertise. As they carry potential risks, nonhuman models might be the best training tool at this moment.

\section{Financial support and sponsorship}

Nil.

\section{Conflicts of interest}

Marc Giovannini is the Founding Editor-in-Chief of the journal. The article was subject to the journal's standard procedures, with peer review handled independently of this editor and his research groups.

\section{REFERENCES}

1. Khoo S, Do ND, Kongkam P. Efficacy and safety of EUS biliary drainage in malignant distal and hilar biliary obstruction: A comprehensive review of literature and algorithm. Endosc Ultrasound 2020;9:369-79.

2. Vanella G, Bronswijk M, Maleux G, et al. EUS-guided intrahepatic biliary drainage: A large retrospective series and subgroup comparison between percutaneous drainage in hilar stenoses or postsurgical anatomy. Endosc Int Open 2020;8:E1782-94.

3. Chandan S, Mohan BP, Khan SR, et al. Efficacy and safety of endoscopic ultrasound-guided pancreatic duct drainage (EUS-PDD): A systematic review and meta-analysis of 714 patients. Endosc Int Open 2020;8:E1664-72.

4. Laique S, Franco MC, Stevens T, et al. Clinical outcomes of endoscopic management of pancreatic fluid collections in cirrhotics vs non-cirrhotics: A comparative study. World J Gastrointest Endosc 2019;11:403-12.

5. Falque A, Gasmi M, Barthet M, et al. Safety and efficacy of EUS-guided pancreatic duct drainage in symptomatic main pancreatic duct obstruction: Is there still a place for surgery? Endosc Int Open 2021;9:E934-42.

6. McCarty TR, Hathorn KE, Bazarbashi AN, et al. Endoscopic gallbladder drainage for symptomatic gallbladder disease: A cumulative systematic review meta-analysis. Surg Endosc 2021;35:4964-85.

7. Bejjani M, Ghandour B, Subtil JC, et al. Clinical and technical outcomes of patients undergoing EUS-guided gastroenterostomy using $20 \mathrm{~mm}$ vs 15 mm LAMS. Endoscopy 2021;Epub 2021 Sep 27.

8. James TW, Greenberg S, Grimm IS, et al. EUS-guided gastroenteric anastomosis as a bridge to definitive treatment in benign gastric outlet obstruction. Gastrointest Endosc 2020;91:537-42.

9. Barthet M, Giovannini M, Gasmi M, et al. Long-term outcome after EUS-guided radiofrequency ablation: Prospective results in pancreatic neuroendocrine tumors and pancreatic cystic neoplasms. Endosc Int Open 2021;9:E1178-85.

10. Moole H, Bechtold ML, Forcione D, et al. A meta-analysis and systematic review: Success of endoscopic ultrasound guided biliary stenting in patients with inoperable malignant biliary strictures and a failed ERCP. Medicine (Baltimore) 2017;96:e5154.

11. Ghandour B, Bejjani M, Irani SS, et al. Classification, outcomes, and management of misdeployed stents during EUS-guided gastroenterostomy. Gastrointest Endosc 2021; August 02, 2021. DOI: 10.1016/j.gie.2021.07.023.

12. Yamamoto $Y$, Ogura T, Nishioka N, et al. Risk factors for adverse events associated with bile leak during EUS-guided hepaticogastrostomy. Endosc Ultrasound 2020;9:110-5.

13. Dhir $\mathrm{V}$, Itoi $\mathrm{T}$, Fockens $\mathrm{P}$, et al. Novel ex vivo model for hands-on teaching of and training in EUS-guided biliary drainage: Creation of "Mumbai EUS" stereolithography/3D printing bile duct prototype (with videos). Gastrointest Endosc 2015;81:440-6.

14. Oh D, Ligresti D, Seo DW. Novel swine biliary dilatation model with temperature-controlled endobiliary radiofrequency ablation: An effective tool for training in EUS-guided biliary drainage. Endosc Ultrasound 2020;9:245-51.

15. Li J, Yao J, Li S, et al. Validation of a novel swine model for training in EUS-FNA (with videos). Endosc Ultrasound 2020;9:232-7. 